\title{
Intoxicação por sal em suínos: aspectos epidemiológicos, clínicos e patológicos e breve revisão de literatura ${ }^{1}$
}

\author{
Juliana S. Brum² ${ }^{2}$ Glauco J.N. Galiza², Ricardo B. Lucena ${ }^{2}$ e Claudio S.L. Barros ${ }^{3 *}$
}

\begin{abstract}
Brum J.S., Galiza G.J.N., Lucena R.B. \& Barros C.S.L. 2013. [Salt poisoning in swine: epidemiological, clinical and pathological aspects and brief review of the literature.] Intoxicação por sal em suínos: aspectos epidemiológicos, clínicos e patológicos e breve revisão de literatura. Pesquisa Veterinária Brasileira 33(7):890-900. Departamento de Patologia, Universidade Federal de Santa Maria, Camobi, Santa Maria, RS 97105-900, Brazil. E-mail: claudioslbarros@uol.com.br

Salt poisoning occurs commonly in pigs by excessive intake of sodium chloride or by a period water deprivation for followed by free access to water. The objective of this work is to aggregate data from cases of salt poisoning, combining existing data in the literature and describe the main clinical and pathological features observed. We reviewed five outbreaks, one of which was carefully monitored. In three of them the intake of sodium chloride had been determined. Clinical signs were basically seizures with the lateral decubitus with paddling movements. Circling was observed in some cases. Sodium determination in muscle of and liver fragments, serum, cerebrospinal fluid and aqueous humor showed increased concentrations of this ion. There was eosinopenia characterizing increased recruitment eosinophils from the circulation into the brain. In all outbreaks eosinophil infiltration was observed in the meninges and the Virchow-Robin space of the cerebral cortex. Cortical laminar necrosis was more pronounced in the brain of pigs from one of the outbreaks in which animals were sick for six days. The combination of these two lesions characterizes the disease. The changes observed result from high concentrations of sodium in the brain causing cause edema that leads to increased intracranial pressure and decreased perfusion to the brain tissue causing diffuse ischemia and neuronal necrosis, with consequent malacia.
\end{abstract}

INDEX TERMS: Swine diseases, sodium concentration, eosinopenia, eosinophilic meningoencephalitis, neuronal necrosis.

RESUMO.- Intoxicação por sal ocorre comumente em suínos por ingestão excessiva de cloreto de sódio ou por privação de água por um período de tempo, seguido de um livre acesso a água abundante. 0 objetivo deste trabalho é agregar dados de casos de intoxicação por sal, diagnosticados, compilar dados já existentes na literatura e caracterizar as principais alterações clínicas e patológicas observadas. Foram revisados cinco surtos, sendo que um deles foi minuciosamente acompanhado. Em três deles a ingestão de cloreto de sódio foi determinada. Os sinais clínicos eram

\footnotetext{
${ }^{1}$ Recebido em 31 de maio de 2013.

Aceito para publicação em 24 de junho de 2013.

${ }^{2}$ Programa de Pós-Graduação em Medicina Veterinária, área de concentração em Patologia Veterinária, Centro de Ciências Rurais, Universidade Federal de Santa Maria (UFSM), Camobi, Santa Maria, RS 97105-900, Brasil.

${ }^{3}$ Laboratório de Patologia Veterinária, UFSM, Camobi, Santa Maria, RS. *Autor para correspondência: claudioslbarros@uol.com.br
}

basicamente convulsões, com intensos tremores musculares e desenvolvimento de opistótono. Os animais permaneciam em decúbito lateral, fazendo movimentos de pedalagem. Alguns andavam em círculos. Dosagens de sódio em fragmentos de músculo e de fígado, no soro, líquor e humor aquoso revelaram concentrações aumentadas do íon. A quantidade de eosinófilos circulantes foi baixa caracterizando grande recrutamento dessas células para o encéfalo. Em todos os surtos foi observada infiltração de eosinófilos nas leptomeninges e no espaço de Virchow-Robin do córtex cerebral. Necrose cortical laminar foi observada mais detalhadamente em um dos surtos onde os suínos estavam doentes há seis dias. A combinação dessas duas lesões caracteriza a doença. Todas as alterações observadas podem ser explicadas pela provável patogenia da doença em que as elevadas concentrações de sódio causam edema cerebral que leva ao aumento da pressão intracraniana e decrésci- 
mo da perfusão para o cérebro causando isquemia difusa e necrose neuronal, com consequente malacia.

TERMOS DE INDEXAÇÃO: Doenças de suínos, concentração de sódio, eosinopenia, meningoencefalite eosinofílica, necrose neuronal.

\section{INTRODUÇÃO}

Intoxicação por sal, também conhecida como toxicidade ao cloreto de sódio ou síndrome da privação de água, ocorre comumente em suínos e aves, e ocasionalmente em ruminantes, cães, cavalos e ovinos (Scarratt et al. 1985, Pringle \& Berthiaume 1988, Thompson 2007, Zachary 2007). Ocorre por ingestão excessiva de cloreto de sódio $(\mathrm{NaCl})$ na ração ou no soro de leite (intoxicação direta) (Radostits et al. 2007); ou pode ocorrer em suínos em dieta com níveis normais de $\mathrm{NaCl}$ onde há privação de água por um período de tempo, seguido de um livre acesso a água abundante. Esta segunda forma da intoxicação é geralmente chamada de síndrome da privação de água ou intoxicação por água (Summers et al. 1995, Radostits et al. 2007, Zachary 2007).

Condições similares são relatadas quando somente o soro é a única fonte de água para os animais (Brito et al. 2001). De fato, em um livro-texto de neuropatologia (Innes \& Saunders 1962), esta condição é referida como "intoxicação por cloreto de sódio (ou por soro de leite)". Restrições no fornecimento de água para suínos, com idade entre quatro e 12 semanas, que são alimentados com rações contendo $2 \%$ de sal, podem resultar em doença clínica (Summers et al. 1995, Radostits et al. 2007). A intoxicação ocorre quando os animais têm acesso ilimitado à água.

O objetivo deste trabalho é agregar dados de casos de intoxicação por sal, diagnosticados pelo Laboratório de Patologia Veterinária na Universidade Federal de Santa Maria, compilar dados históricos já existentes na literatura através de uma breve revisão de literatura e caracterizar as principais alterações clínicas e patológicas observadas nessa condição.

\section{REVISÃO BIBLIOGRÁFICA}

Em 1856 um clínico relatou uma doença que acometeu 13 porcos em uma propriedade localizada no município de Augsburg, Alemanha. Os suínos tinham entre 6 e 8 meses de idade. Estavam alojados em duplas ou trios, em pocilgas bem estruturadas, e eram alimentados com o resíduo de uma cervejaria misturado com água. Em abril, o alimento dos porcos foi misturado a uma salmoura. No dia seguinte, alguns animais apresentaram hiporexia. Progrediram para um estado de vertigem e sentavam como cães. Houve episódios de convulsão, decúbito e contrações espasmódicas dos membros posteriores. Em um curto período de tempo, os suínos andavam de cabeça baixa e a pressionavam contra a parede. Não foram observadas alterações significativas na necropsia. Muitas pessoas também haviam se alimentado com a mesma comida e não apresentaram alterações. A etiologia da doença foi atribuída à mistura da salmoura no alimento dos animais (Morton \& Simonds 1856).

Alguns meses depois, foram publicados no mesmo peri- ódico - The Veterinarian - outros relatos de casos semelhantes. Muitos desses casos haviam ocorrido anteriormente ao caso inicial, porém não haviam sido divulgados. Parece que a primeira descrição estimulou outros médicos veterinários do continente europeu a se manifestassem a respeito da enfermidade que observavam em suínos. Em uma destas descrições (Lepper 1856), o veterinário relata que ocasionalmente observava casos de morte de porcos após a ingestão de salmoura desde o ano de 1816, na região de Kent, Inglaterra. Nesta localidade, a doença era conhecida como "staggers" (cambaleira) e por muitos anos a etiologia foi atribuída a um osso localizado da porção palatina da boca ("stagger-bone"). Acreditava-se que a cura era realizada a partir da remoção deste osso e recuperação dos animais após a cirurgia. Logo, soube-se que os suínos que sobreviveram à prática, iriam recuperar-se mesmo sem a remoção óssea. Muitos suínos saudáveis, incluindo leitões, eram submetidos à retirada do osso para prevenção da doença.

Ainda no mesmo ano (Corby 1856), houve o relato de uma doença caraterizada por trismo acometendo duas porcas em Andover, Inglaterra. Uma delas abortou poucos dias após ter ingerido o alimento misturado à salmoura e estava muito debilitada. A outra porca, que também havia recebido a mesma alimentação, estava amamentando e pareceu ser menos afetada, porém sessou a produção de leite. Ambas foram medicadas e a que havia abortado morreu dez dias depois. Em Monmouth, Inglaterra, no mês seguinte, foi informado que um lote de suínos (uma fêmea com onze leitões e quatro outros adultos) de uma fazenda desenvolveu uma enfermidade, caracterizada por andar cambaleante e cabeça pendente (Lewis 1856). Um dos porcos vomitou. Apenas cinco leitões se recuperaram quando forçados a ingerirem leite. 0 diagnóstico final de intoxicação por sal comum foi estabelecido baseado na dosagem de sal presente no conteúdo estomacal (42 gramas de sal comum) e acredita-se que por falta de informação foi adicionada salmoura na alimentação dos animais. Ainda no mesmo periódico, no final do ano, conclui-se que realmente há intoxicação por salmoura em porcos quando se descreve o relato de outro fazendeiro que perdeu animais com sintomatologia semelhante também devido à adição de salmoura à alimentação (Gamgee 1856). Na ocasião, a doença foi chamada de "bad distemper". Até essa época, apesar dos sinais clínicos neurológicos bastante expressivos e característicos, as lesões macroscópicas observadas eram restritas ao trato gastrointestinal e aliadas à clínica e à epidemiologia, suficientes para o diagnóstico final (Slavin \& Worden 1941, Morton \& Simonds 1856).

No final do século XIX, a morte de muitos suínos após a ingestão de salmoura foi atribuída à presença de ptomaína. 0 sal desempenhava apenas um papel secundário no desenvolvimento da doença. Na necropsia as lesões começaram a ser restritas no sistema nervoso central e caracterizavam-se por hemorragia e edema cerebral. Em um estudo de um surto não foram observadas lesões no estômago e no intestino. Nessa época outro autor relatou, na Suíça, que a intoxicação por cloreto de sódio era semelhante à intoxicação por salmoura, levantando a hipótese de que era 
somente o cloreto de sódio o causador da doença. 0 mesmo foi observado em estudos na Alemanha, onde, por algum tempo, a doença foi tratada como erisipela e logo depois passou a ser conhecida como "Vergiftung durch Heringslake" (envenenamento por arenque) e, por fim, a partir de 1907, "Vergiftung durch Kochsalz" ou "Kochsalzvergiftung" (envenenamento por sal) (Smith 1955). O mesmo autor (Smith 1955) descreve ainda uma sequência de outros surtos ocorridos em diferentes situações e locais. Em Gardelegen e em Hameln, Alemanha, os animais ingeriram sobras de uma fábrica de conservantes; outros casos ocorreram pela ingestão de sobras de uma padaria; restos de comida humana nos Estados Unidos; leitelho; e sobras de comida humana erroneamente contendo um sabão em pó próprio para lavar louça, contendo grande quantidade de carbonato de sódio (Smith 1958). Relata ainda que a intoxicação só acontecia por erros de manejo ou desconhecimento do tratador. Um exemplo disso foi em Gladbach, Alemanha, onde um tratador com perturbação mental adicionou um saco de sal no alimento dos suínos.

Com o início da Primeira Guerra Mundial, a Alemanha sofreu escassez de alimentos ricos em proteína e precisou começar a importar. 0 peixe conservado em salga passou a ser importado, o que desencadeou muito casos de intoxicação por sal em suínos. A partir desses casos foi desenvolvido um método de diagnóstico baseado na obtenção de uma grande quantidade de cristais a partir de um extrato aquoso do conteúdo do intestino grosso. Esses cristais podiam ser identificados como cloreto de sódio com o uso de uma chama e nitrato de prata (Smith 1955).

Em 1941, devido ao fato de se considerar a extrema sensibilidade de suínos ao sal, foram realizados experimentos. Os suínos eram forçados a consumir quantidades crescentes de sal comum e, no fim de 48 horas, não foram observadas alterações nos animais (Slavin \& Worden 1941). Os mesmo autores em publicação de 1926 especificaram possíveis doses intoxicantes para diferentes espécies, e em outra de 1934, relatam que se suspeitava que a intoxicação ocorria devido à toxina de uma bactéria presente na salmoura. Relatam também que na Alemanha suspeitava-se que havia um ácido graxo presente na salmoura, engendrado pelo calor; que em Stratford-on-Avon, Inglaterra, a salmoura estava impregnada com chumbo; e relatam ainda surtos de intoxicação por sal comum, em diferentes situações, nos anos de 1918, 1927, 1930, 1935 e 1940. Em algumas dessas situações foram realizados experimentos com coelhos, pássaros e potros obtendo-se pouco sucesso.

Os benefícios da inclusão do sal na dieta suína foram descritos em 1947 no Wisconsin Agricultural Experiment Station Bulletin (Grummer \& Bohstedt 1947). Relatam que a adição do produto economizava $\$ 20$ em alimento a cada dólar de sal usado em um experimento desenvolvido na Universidade de Wisconsin. Os porcos alimentados com sal ganharam até 662 gramas diariamente, comparados com 571 gramas ganhas com um óleo de milho e soja sem sal. Seguida das vantagens obtidas com a adição do sal há uma interrogação dos mesmos autores da possibilidade de morte de suínos intoxicados com sal. A partir deste ponto, desenvolveram vários experimentos e concluíram que $2 \%$ de sal na dieta suína não causa a morte e que resíduo de queijo fresco, apesar de apresentar dosagens altas de sal, pode ser administrado aos animais. No final da década de 1940, concluiu-se que a intoxicação resultava de um grande fornecimento de sal aos animais, sem o suplemento de água adequado (Smith 1955). No livro Lander's Veterinary Toxicology há o seguinte parágrafo: "É aceitável que altas doses de cloreto de sódio podem levar a intoxicação, particularmente de suínos e aves, embora deva ser mencionado que a evidência para isso é amplamente circunstancial. Uma dieta contendo uma alta proporção de sal não é rapidamente ingerida pelos animais e tentativas de produzir a intoxicação experimental por sal não obtiveram muito sucesso" (Nicholson 1945). Há a sugestão de que a intoxicação ocorra pela remoção da água das células (dissecação) e simultâneos desequilíbrios iônicos. Esse fenômeno envolve o sistema nervoso central, causando convulsões, paralisia, inconsciência e coma (Smith 1955).

0 primeiro relato de intoxicação por sal experimental com total sucesso foi realizado da University of Wisconsin em 1954 (Bohstedt \& Grummer 1954). Os autores discutem se o termo "intoxicação" é adequado ou se a doença trata-se apenas de uma alta concentração de cloreto de sódio nos tecidos vitais que leva à desidratação fatal. Também descrevem a possibilidade de outros fatores, como privação de água, estarem envolvidos na patogenia da doença. Tentando resolver estas questões, realizam o experimento. Por fim, concluem que a ingestão de sal em suínos pode ocorrer desde que as proporções sejam constantes e não ultrapassem $2 \%$ da quantidade total de ração; que deve haver cochos para todos os animais; e que o sal torna-se palatável quando oferecido em meio a uma fonte líquida (soro de queijo ou salmoura, por exemplo) e que o insucesso dos experimentos anteriores se deve ao fato de grandes quantidades serem administradas em meio sólido.

No final da década de 1950, a intoxicação por sal em suínos ainda era considerada um enigma, porém muito já se sabia sobre a doença. A doença acometia predominantemente os porcos em relação a outras espécies (Padovan 1980, Pearson \& Kallfelz 1982). Acreditava-se que isso acontecia porque os porcos eram criados com grande negligência e que a comida fornecida a eles era sempre de qualidade duvidosa e mal armazenada (Smith, 1958). Por muito tempo os suínos foram alimentados quase que exclusivamente de uma mistura de restos de alimentos e água (Vianna 1976). Nessa época a salmoura era um dos principais conservantes alimentares. Este processo era muito aplicado na conservação por salga ou salmoura de peixes (bacalhau), carnes (porco), vegetais (chucrute) (Smith 1958). Como a alimentação dos porcos era a base desses restos conservados em salga, essa era a principal forma pela qual os suínos acabavam ingerindo grandes quantidades de cloreto de sódio. Nessa época, a doença foi enquadrada como uma condição do sistema nervoso central e estudos histológicos do encéfalo começaram a ser difundidos (Cox \& Pitts 1957, Done et al. 1957, Gellatly 1957, Sautter et al. 1957, Smith 1957, Done et al. 1959, Rac et al. 1959, Satoh 1961, Innes \& Saunders 1962, Dow et al. 1963, Arieff \& Guisado 1976, Wells et al. 1984, Summers et al. 1995). 
Sabe-se que a etiologia da doença baseia-se em ingestão de grandes quantidades de sal comum (cloreto de sódio) ou, privação de água, seguido de um livre acesso à água abundante mesmo com ingestão de quantidade normal de $\mathrm{NaCl}$ (por isso também a doença é conhecida como síndrome da privação de água ou intoxicação por água) (Carson 2006). Ração e água contendo grandes quantidades de sal não são palatáveis para os animais, mas excessivas quantidades de sal são, algumas, vezes ingeridas, especialmente em águas salgadas (Smith 1955). Para suínos, a dose tóxica é de $2,2 \mathrm{~g} / \mathrm{kg}$ de peso vivo (PV) (Radostits et al. 2007). 0 mesmo pode ser aplicado a equinos e bovinos e, em ovinos a dose tóxica é maior, 6,0g/ $\mathrm{kg}$ de PV. Esta dose é altamente influenciável pela idade e peso corporal.

Atualmente, a ingestão direta de sal comum puro juntamente com a alimentação já é menos comum, mas pode ocorrer, principalmente quando os animais são privados do sal seguido por um acesso ilimitado, ou de uma quantidade exagerada na ração (Carson 2006). Hoje, a principal forma de intoxicação dos suínos é chamada de intoxicação indireta, em que há o desequilíbrio no fornecimento de água (Summers et al. 1995, Carson 2006). As principais fontes de toxicidade para suínos são: fornecimento de água com alto teor de $\mathrm{NaCl}$, principalmente água de poço artesiano, aos animais com sede; acúmulo de água em cochos de sal, principalmente durante período seco; alimentação dos animais com resíduos de padaria, resíduos de fábrica de queijo, salmoura de açougues e restos de peixe salgado (Radostits et al. 2007, Thompson 2007). Tratamento com sulfato de sódio, realizado para edema intestinal, também é implicado como fonte de toxicidade, caso haja privação de água; e contaminação ambiental por petróleo que apresenta um sabor salgado (Radostits et al. 2007).

Existem alguns fatores de risco que podem aumentar a probabilidade de intoxicação por sal. Suínos, aves, equinos e vacas de leite em lactação são mais susceptíveis que bovinos de corte, vacas de leite secas e ovinos. Águas salinas contendo níveis altos de outros elementos como flúor ou magnésio, podem ser mais tóxicas. Dessa maneira, a toxicidade de águas de poço depende da quantidade de sulfatos, carbonatos e cloretos. 0 ambiente também pode influenciar na intoxicação. Desde 1856 já se acreditava que a temperatura ambiental tinha influência no desenvolvimento da doença (Gamgee 1856). Parece que no verão a água apresenta níveis de sal mais tóxicos que no inverno (Radostits et al. 2007).

A patogênese das lesões cerebrais na intoxicação por sal em suínos é pouco entendida (Summers et al. 1995), mas acredita-se que o edema cerebral agudo ocorra provavelmente devido à correlação osmótica necessária para diminuir os níveis de sal no cérebro, quando há reestabelecimento de água, após restrição. 0 sódio é o principal cátion e o cloreto é o principal ânion que regulam o balanço osmótico do fluido extracelular do corpo (Thompson 2007). A desidratação provocada pelas altas quantidades de sal resulta em aumento da pressão osmótica no trato alimentar e desencadeia uma irritação na mucosa. Se o sal é absorvido gradualmente há um acúmulo do íon sódio nos tecidos, principalmente no cérebro (Radostits et al. 2007).
O acúmulo de altos níveis de sódio pode inibir a glicólise anaeróbica, impedindo o transporte ativo de sódio para fora do compartimento cérebro-espinhal. Adicionado a isto, o aumento da pressão intracraniana poderia levar ao decréscimo da perfusão para o cérebro, causando dano ao parênquima dependente da severidade e duração da isquemia. 0 grande aumento na pressão intracraniana pode causar isquemia difusa, tanto temporária como permanente (Radostits et al. 2007, Finnie et al. 2010).

\section{MATERIAL E MÉTODOS}

Foram revisados todos os protocolos de necropsia e exames histopatológicos, arquivados no LPV-UFSM, realizados entre janeiro de 1964 e dezembro de 2011, na busca de casos de intoxicação por sal em suínos. Os protocolos referentes a esses casos foram separados e avaliados. Desses protocolos foram retiradas informações quanto à idade, à história clínica, às descrições macroscópicas e às descrições histopatológicas.

A esses dados foram adicionados os dados de um surto da doença acompanhado pela visita realizada pelos autores a uma propriedade rural, situada no município de São Domingos (latitude $26^{\circ} 56^{\prime}$ S, longitude 52 $53^{\prime} 0$ ), no estado de Santa Catarina. Dados da doença clínica e manejo dos suínos foram observados e minuciosamente colhidos juntamente com o médico veterinário responsável, com o proprietário e com o tratador. Nesse surto, dos animais que se encontravam mortos na hora necropsia (total de 13 suínos) foi colhido o encéfalo, armazenado em formol a $10 \%$, processado rotineiramente para histopatologia e corado pela hematoxilina e eosina. Também foram colhidos fragmentos de fígado e pulmão de sete destes animais, coração de dois animais e intestino de um destes animais para realização do mesmo procedimento. Três desses suínos foram necropsiados no dia do início dos sinais clínicos; os demais, seis dias após o princípio da doença, sempre imediatamente após a morte.

Dos animais que foram eutanasiados in extremis (total de 15 animais) seis dias após o início dos sinais clínicos, foram colhidos, antes da morte, $3,0 \mathrm{ml}$ de sangue da veia jugular. 0 sangue foi acondicionado em tubos sem anticoagulante para extração do soro. Também desses animais, para realização de contagem de eosinófilos, foram colhidos $3,0 \mathrm{ml}$ de sangue acondicionado em tubos com o anticoagulante ácido etilenodiaminotetracético (EDTA). Previamente à necropsia de sete dos suínos eutanasiados, foi colhido líquor do espaço atlanto-occipital e humor aquoso de um dos globos oculares dos 15 suínos submetidos à eutanásia. Imediatamente a necropsia foi realizada. Fragmentos de músculo e fígado foram colhidos em sacos plásticos individuais. Esses materiais foram mantidos em refrigeração. Os encéfalos foram retirados, assim como fragmentos de adrenal, fígado e rim foram colhidos, e armazenados em formol a 10\%. Também foram colhidos fragmentos de pulmão de 11 suínos, fragmentos de coração de cinco porcos e fragmento de intestino de um dos suínos eutanasiados, com posterior fixação em formol a $10 \%$. Todos os fragmentos foram processados rotineiramente para histopatologia e corados pela hematoxilina e eosina.

Com o sangue total de 11 suínos, para determinação da quantidade de eosinófilos circulantes, foi utilizado um diluente específico (líquido de Dunger), montagem em câmara de Neubauer e leitura em microscópio de luz. O soro, o líquor, o humor aquoso e os fragmentos de músculo e fígado colhidos, foram encaminhados para análise da concentração de sódio. As dosagens de sódio nos fragmentos de músculo e fígado foram realizadas pela metodologia EEA/Chama Ar-Acetileno e digestão com ácido nítrico em sistema fechado (Standard Methods $21^{\text {st }}$ ). No caso do líquor, soro 
e humor aquoso as concentrações de sódio foram realizados pelo método de fotometria de chama.

Para a caracterização do tipo, intensidade e a distribuição das lesões encefálicas, os encéfalos dos 28 suínos do último surto, foram seccionadas transversalmente em intervalos de $1-2 \mathrm{~cm}$ para exame macroscópico. Foram selecionadas as seguintes seções para exame histológico: 1) bulbo na altura do óbex, 2) cerebelo, 3) ponte com pedúnculos cerebelares, 4) mesencéfalo na altura dos colículos rostrais, 5) tálamo, 6) hipocampo, 7) telencéfalo occipital, 8) telencéfalo sobre o tálamo, e 9) telencéfalo frontal na altura do joelho do corpo caloso e dos núcleos basais. As lesões observadas no encéfalo foram graduadas de 1-3, de acordo com a intensidade. Essa graduação foi realizada de acordo com a média de percepção subjetiva de três patologistas que examinaram as lâminas. Os seguintes aspectos foram computados para a obtenção da intensidade das lesões: 1) edema do neurópilo, 2) tumefação das células endoteliais, 3) infiltrado inflamatório, 4) meningite, 5) gliose focal, 6) neurônios vermelhos (neurônios com o citoplasma encolhido e eosinofílico e núcleo picnótico), 7) neuronofagia, 8) malacia (necrose do componente neuroectodérmico com manutenção das estruturas mesenquimais e infiltrado de macrófagos tumefeitos e com citoplasma espumoso [células Gitter]), 9) lesão residual (estruturas vasculares e células Gitter remanescentes, formando uma estrutura cavitária semelhante a um cisto) e 10) hiperemia. Cada um dos parâmetros avaliados foi relacionado à seção anatômica examinada, com o objetivo de determinar a localização das lesões produzidas por essa intoxicação no SNC. Adicionalmente, foi avaliado qualitativamente o tipo de infiltrado inflamatório.

\section{RESULTADOS}

Durante o período de revisão (48 anos) dos protocolos, foram encontrados cinco surtos de intoxicação por sal em suínos. Os casos ocorreram em 1971 (Surto 1), 1982 (Surto 2), 1985 (Surto 3), 2009 (Surto 4) e 2011 (Surto 5).

Surto 1. Foi remetida uma porca sem histórico ou dados epidemiológicos. Na necropsia apresentava-se em regular estado corporal, com escasso tecido adiposo e não foram observadas alterações significativas. Na histologia observou-se congestão do encéfalo e meningoencefalite eosinofílica.

Surto 2. Foi remetido um suíno, macho, sem raça definida, com 8 meses de idade. Este porco foi alimentado com restos de comida e canjica cozida com sal. Logo iniciou com movimentos em círculo, inapetência e salivação. No dia seguinte manteve-se em decúbito e apresentava diarreia líquida e fétida. Na necropsia apresentava-se em péssimo estado corporal e desidratado. As mucosas estavam congestas e havia hiperemia encefálica. Não foram observadas outras alterações significativas. Histologicamente observou-se congestão do cerebelo e do telencéfalo. Na região talâmica além da congestão, havia focos de gliose e infiltrado perivascular eosinofílico.

Surto 3. Foi realizada necropsia em um suíno, macho, Landrace, com 5 meses de idade. Era o único animal da propriedade e recebeu salmoura, juntamente com restos de comida e ração. Iniciou com vocalização rouca e salivação brancacenta. Morreu em duas horas. Não foram observadas alterações significativas da necropsia. Os achados histológicos foram de congestão no cerebelo e bulbo. No telencéfalo havia intenso infiltrado inflamatório eosinofílico ao redor dos vasos sanguíneos das meninges e da substância branca.

Surto 4. Foi encaminhado para necropsia um suíno, macho, sem raça definida, com 3 meses de idade. Na propriedade morreram cinco leitões da mesma faixa etária em dez dias. Eram mantidos com animais de diferentes idades, totalizando 30 suínos. Apresentavam depressão, anorexia, andar em círculos, posição de cão sentado, decúbito, febre, opistótono e salivação. Não foram observadas alterações significativas macroscopicamente e na histologia observou-se meningoencefalite eosinofílica (Fig.1 e Fig.2) acentuada nas seções de telencéfalo examinadas.

Surto 5. No último surto, 680 suínos de crescimento e terminação de ambos os sexos foram transferidos de uma unidade de produção de suínos (Propriedade 1) para outra propriedade distante $13 \mathrm{~km}$ (Propriedade 2). Após chegada à Propriedade 2, os porcos foram alimentados com uma ração comercial e foi disponibilizado soro de leite proveniente de uma fábrica de queijo das proximidades. Na maior parte do tempo não era fornecido água e a única fonte de bebida era o soro de leite, administrado através de

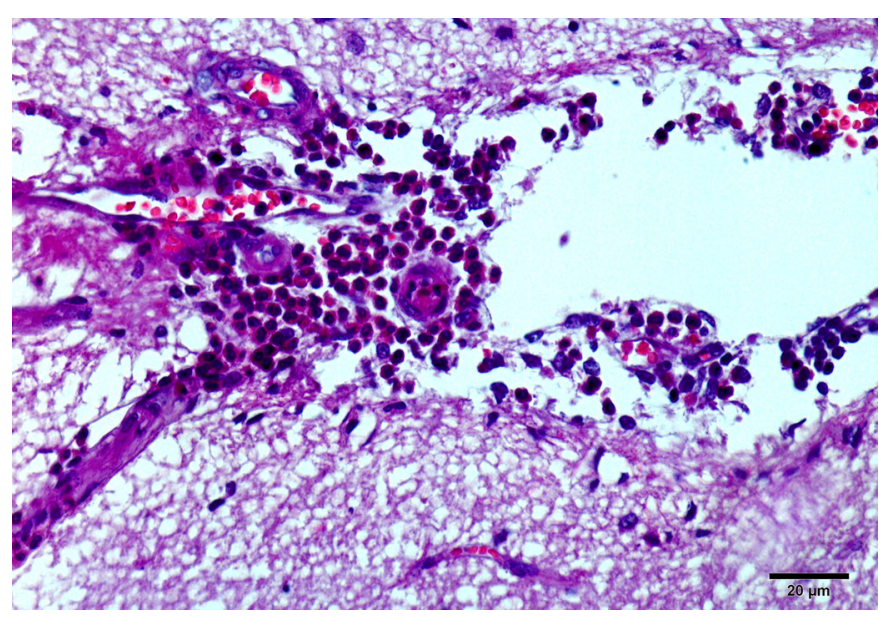

Fig.1. Intoxicação por sal em suínos. Observa-se na leptomeninge de uma seção de telencéfalo acentuado infiltrado inflamatório constituído de eosinófilos. HE, obj.40x.

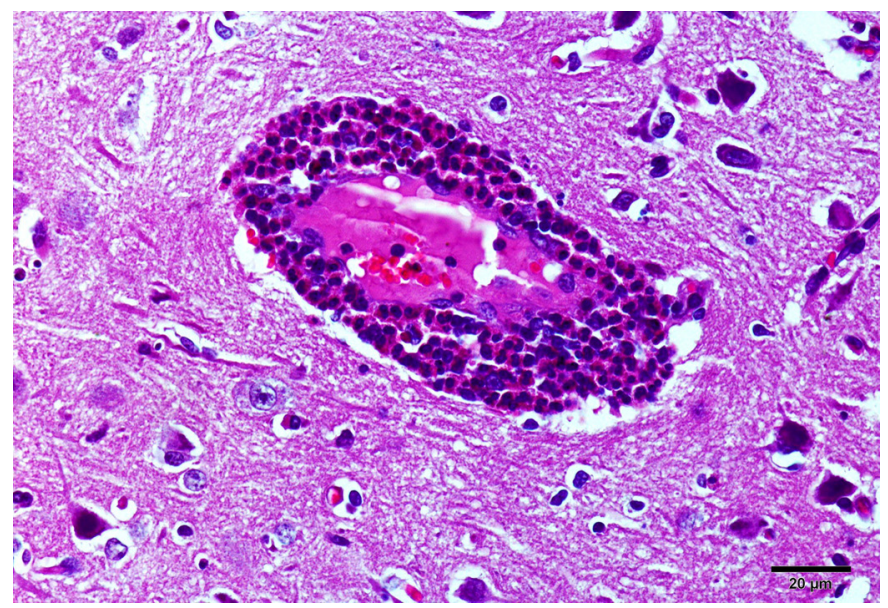

Fig.2. Intoxicação por sal em suínos. Observa-se no espaço de Virchow-Robin de uma seção de telencéfalo acentuado infiltrado inflamatório constituído de eosinófilos. HE, obj.40x. 
um sistema de tubulação até os bebedouros. 0 fornecimento soro foi algumas vezes interrompido quando este não estava disponível e então era substituído por água pura. Ocasionalmente os tubos ficavam obstruídos devido à grande quantidade de gordura presente no soro e os leitões eram privados de qualquer fonte de bebida. Antes de chegar à Propriedade 2, os leitões nunca haviam ingerido soro de leite. Dois dias após, foram observados os primeiro suínos doentes. Em seis dias, 370 leitões $(54,41 \%)$ morreram ou foram submetidos à eutanásia in extremis (Fig.3). Nos animais da Propriedade 1 nenhuma alteração foi relatada.

Os sinais clínicos eram variados, mas claramente se observava envolvimento neurológico. Os sinais descritos a seguir foram observados em mais de uma centena de leitões. Houve episódios recorrentes de convulsões, onde os animais apresentavam intensos tremores musculares e desenvolvimento de opistótono. Quando eram colocados sentados, a cabeça permanecia em posição quase vertical. Frequentemente os leitões tinham convulsões clônicas que forçava os animais a ficar em decúbito lateral ou esternal e a permanecer com os membros esticados, fazendo movimentos de pedalagem (Fig.4). Alguns andavam em círculos; outros estavam em decúbito lateral ou esternal, não res-

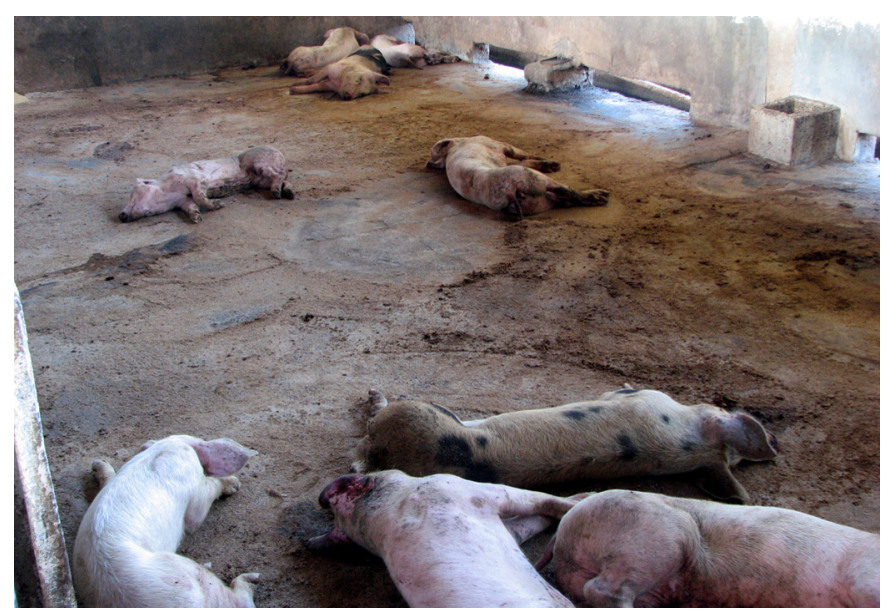

Fig.3. Intoxicação por sal em suínos. Grande quantidade de animais mortos após seis dias de sinais clínicos.



Fig.4. Intoxicação por sal em suínos. Leitão em decúbito lateral e apresentando movimentos de pedalagem.



Fig.5. Intoxicação por sal em suínos. Leitão em decúbito esternal apresentando marcada apatia.

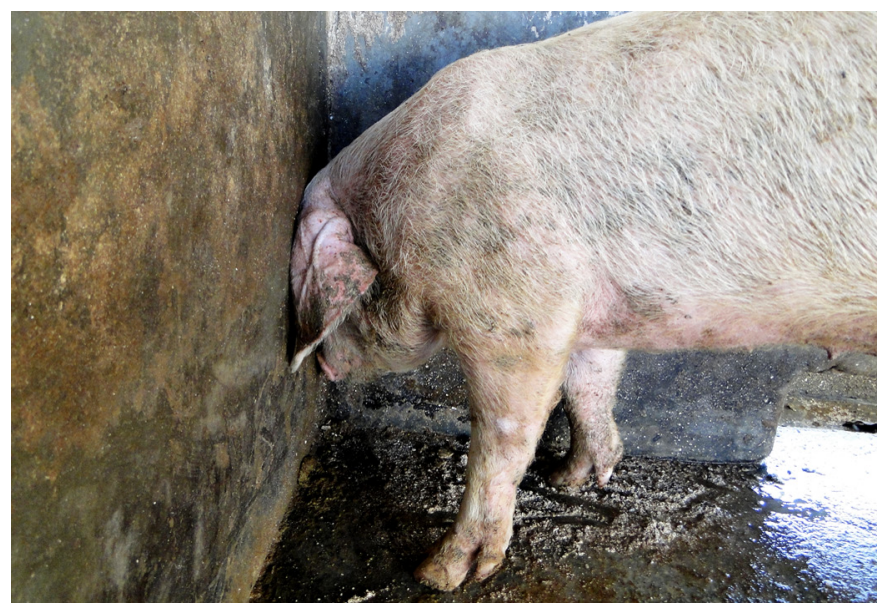

Fig.6. Intoxicação por sal em suínos. Leitão pressionando a cabeça contra a parede.

ponsivos aos estímulos do ambiente (Fig.5). Os episódios de convulsões ocorriam mais ou menos em intervalos constantes e duravam vários minutos. Nessas horas, os leitões andavam sem rumo, aparentemente cegos e pressionavam a cabeça contra objetos (Fig.6). Nessa fase os leitões mostravam-se deprimidos e não guinchavam quando manejados ou contidos. A temperatura corporal, verificada em cinco animais, estava dentro dos limites normais. Os animais mais velhos adoeceram ocasionalmente.

Vinte e oito necropsias foram realizadas e os achados macroscópicos foram considerados incidentais. Em aproximadamente $60 \%$ dos leitões necropsiados observaram-se lesões típicas de broncopneumonia por Mycoplasma spp. Em cinco casos havia aderências fibrosas e fibrina entre as membranas epicárdicas e pericárdicas, o que foi interpretado como pericardite em resolução, possivelmente devido à infecção por Haemophilus parasuis. Nenhuma alteração foi observada no trato gastrointestinal. Os achados macroscópicos no sistema nervoso central consistiam em hiperemia das leptomeninges e leve achatamento dos giros telencefálicos. Ao corte seriado do encéfalo de três suínos foram observadas áreas multifocais amareladas (interpretado como malacia) (Fig.7). Com exposição à lâmpada de Wood 
(Jackman \& Edwin 1983), estas áreas tornam-se levemente esverdeadas. Não foram observadas alterações histológicas em todas as seções de fígado, adrenal, intestino e rim analisadas. Nas seções de pulmão e coração foram observadas lesões leves ou moderadas referentes aos achados descritos macroscopicamente para estes órgãos.

Microscopicamente nas seções de encéfalo observavam-se dois padrões de lesão, conforme o tempo de evolução dos sinais clínicos. Somente nos três leitões necropsiados logo após o início dos sinais clínicos observou-se, no espaço de Virchow-Robin e nas leptomeninges das seções de telencéfalo, acentuado infiltrado inflamatório constituído de eosinófilos. Em outros 18 suínos necropsiados seis dias após o início dos sinais clínicos, observou-se infiltrado predominantemente mononuclear, moderado ou acentuado, no espaço de Virchow-Robin nas mesmas seções (Fig.8). Em nove desses animais, havia ainda meningite mononuclear (Fig.9). As lesões mais significativas, observadas em todos os leitões, independentemente da evolução clínica, foi a acentuada ne-

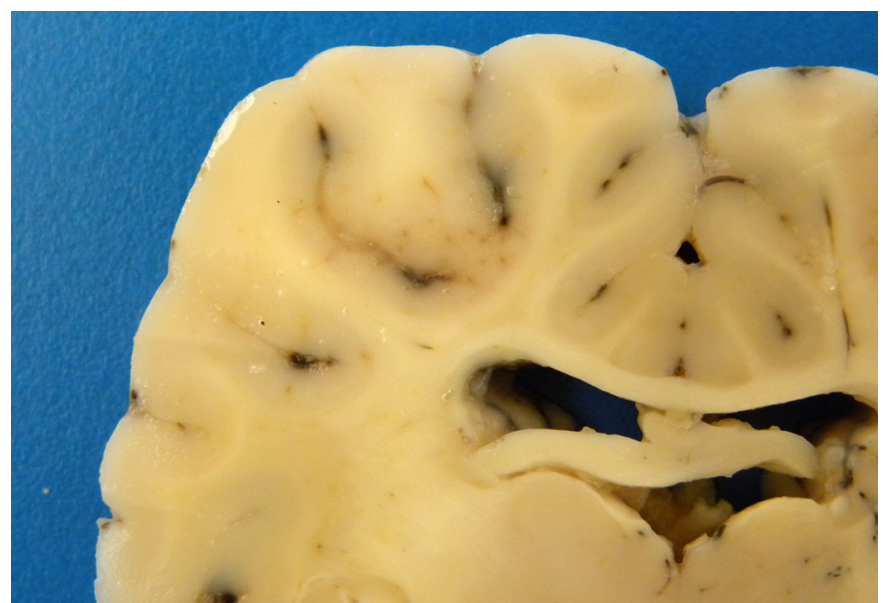

Fig.7. Intoxicação por sal em suínos. Em uma seção transversal de um encéfalo, na região do telencéfalo, há áreas amareladas que se tornam levemente esverdeadas com exposição à lâmpada de Wood.

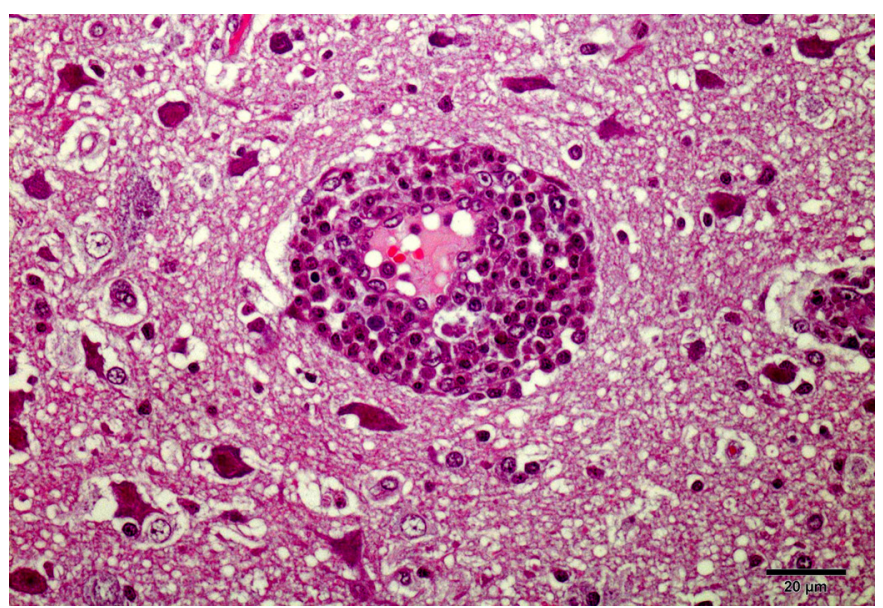

Fig.8. Intoxicação por sal em suínos. Observa-se no espaço de Virchow-Robin de uma seção de telencéfalo acentuado infiltrado inflamatório constituído predominantemente de células mononucleares em suíno eutanasiado seis dias pós-intoxicação. HE, obj.40x.

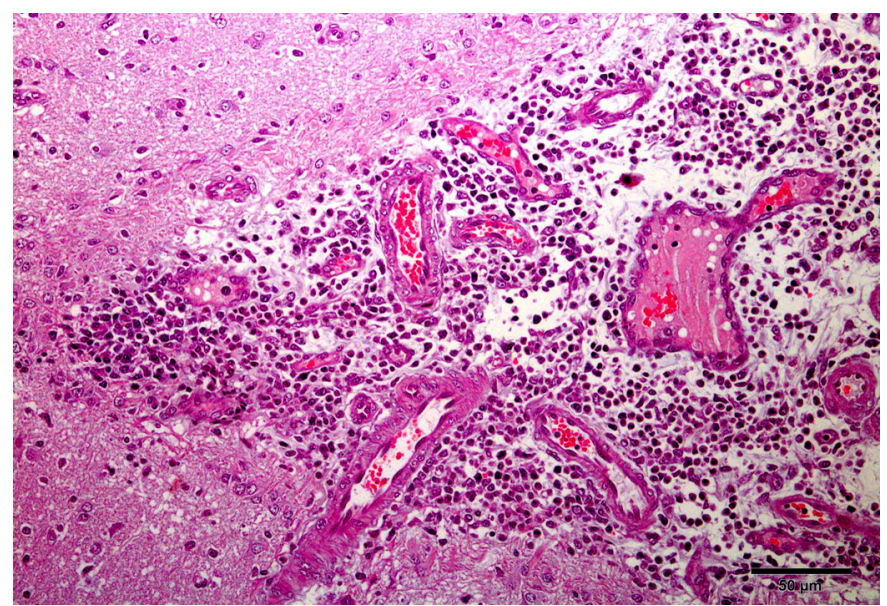

Fig.9. Intoxicação por sal em suínos. Observa-se leptomeninge de uma seção de telencéfalo acentuado infiltrado inflamatório constituído predominantemente de células mononucleares em suíno eutanasiado seis dias pós-intoxicação. HE, obj.20x.

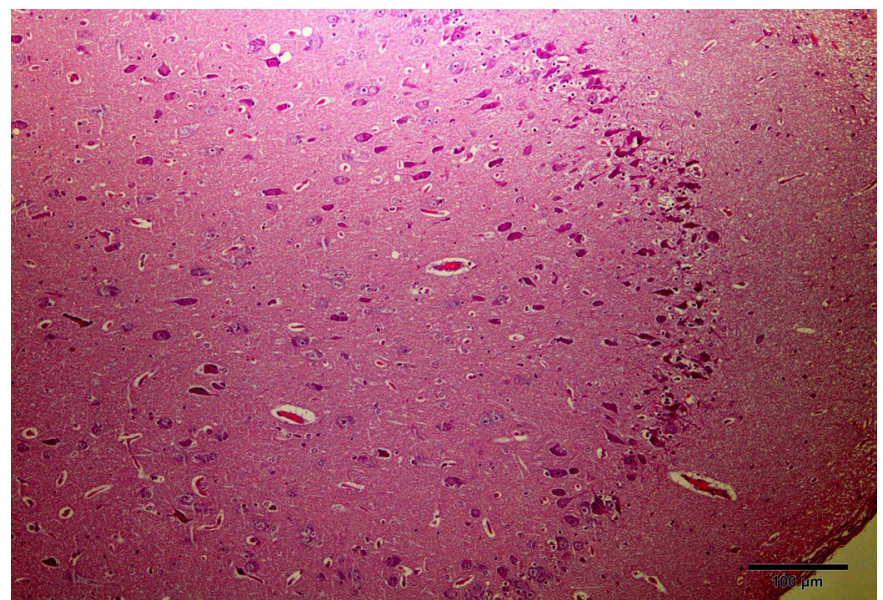

Fig.10. Intoxicação por sal em suínos. Há acentuada necrose neuronal laminar em uma seção de telencéfalo. HE, obj.10x.

crose neuronal laminar (Fig.10) e marcada vacuolização perineuronal (espongiose - edema cerebral) (Fig.11). Os neurônios necróticos eram angulares e encolhidos, com núcleo picnótico ou ausente; e o citoplasma vermelho (neurônios vermelhos de isquemia). Essas duas alterações eram acentuadas na maioria dos encéfalos e predominavam nas seções de telencéfalo frontal, parietal e occipital; também eram observadas moderadamente nas seções de hipocampo, tálamo e núcleos da base; eram ausentes ou leves nas seções de mesencéfalo, ponte, cerebelo e bulbo. Comum a todos os leitões que tiveram morte natural, havia hiperemia acentuada e os capilares eram proeminentes devido ao acentuado edema das células endoteliais, predominantemente nos locais de maior lesão (Fig.12). Associada as áreas de necrose neuronal havia malacia do neurópilo em 25 suínos (Fig.13). Nessa região, havia perda da definição do tecido e grande quantidade de macrófagos espumosos (células gitter) (Fig.14). Esse aspecto predominava acentuadamente nas seções de telencéfalo parietal e occipital; moderadamente nas seções de telencéfalo frontal; leve nas seções de hipocampo, núcleos da base; e ocasional nas seções de tálamo. Em sete se- 


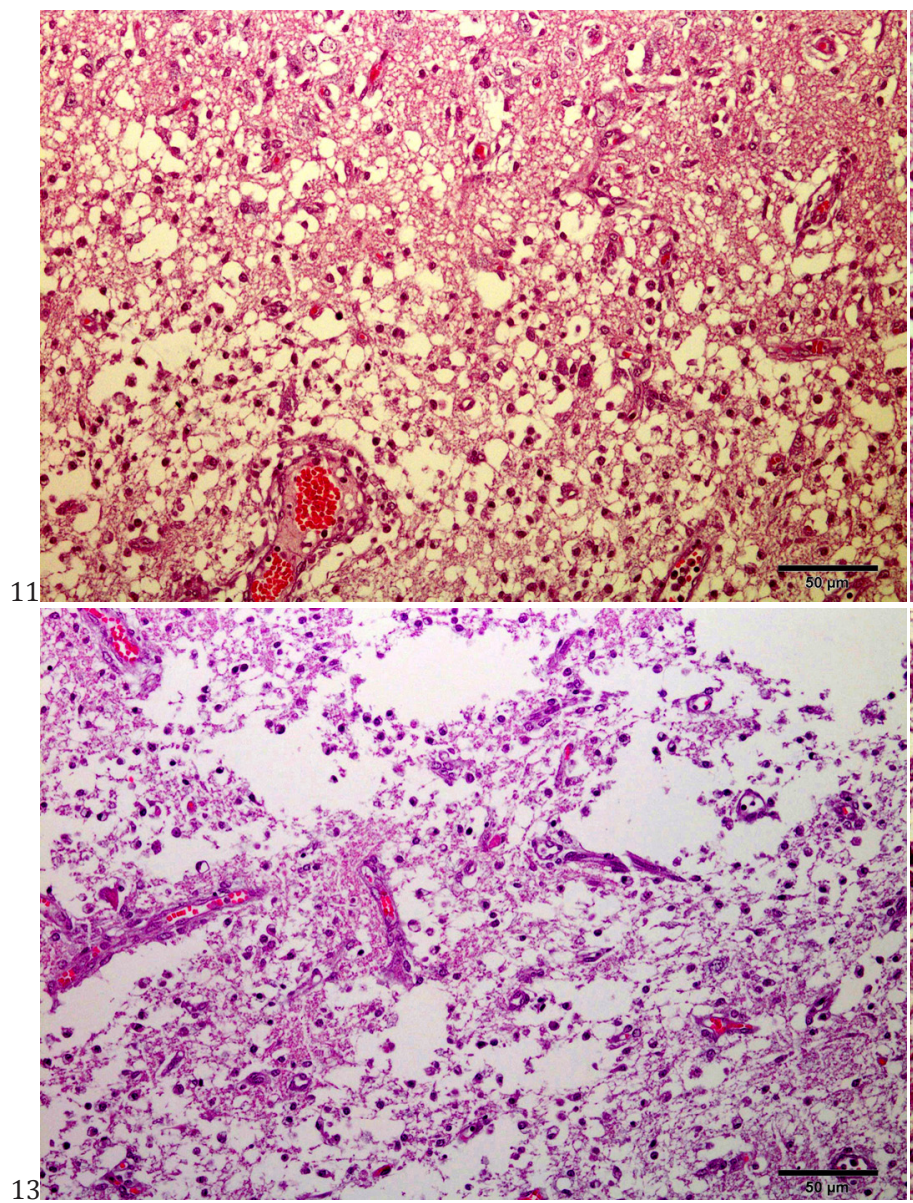

Fig.11. Intoxicação por sal em suínos. Observa-se marcada vacuolização perineuronal (espongiose - edema cerebral). HE, obj.20x.

Fig.13. Intoxicação por sal em suínos. Seção de telencéfalo apresentando malacia acentuada. HE, obj.20x.

ções de telencéfalo são observadas cavitações do neurópilo. Neuronofagia foi observada levemente em seis encéfalos, associada às seções de necrose neuronal. Gliose também foi observada em onze encéfalos e de intensidade leve.

Após a contagem dos eosinófilos em quatro quadrados laterais maiores da câmara de Neubauer de cada amostra, observou-se que em sete suínos a quantidade de eosinófilos circulantes era nula. Em quatro amostras a quantidade de eosinófilos foi variável: 50 células/ $\mu \mathrm{L}$ de sangue, 200 células/ $\mu \mathrm{L}$ de sangue, 550 células/ $\mu \mathrm{L}$ de sangue e 1.150 células/ $\mu \mathrm{L}$ de sangue.

Os resultados das dosagens de sódio no músculo, fígado, soro, líquor e humor aquoso estão no Quadro 1.

\section{DISCUSSÃO}

Baseado na epidemiologia, sinais clínicos (Cox \& Pitts 1957, Done et al. 1959, Radostits et al. 2007) e/ou lesões histológicas (Smith 1957, Innes \& Saunders 1962) observadas nos cinco surtos descritos, o diagnóstico de intoxicação por sal foi concluído.

Em três surtos (2, 3 e 5) onde constavam dados epidemiológicos descritos havia menção de ingestão de sal co-

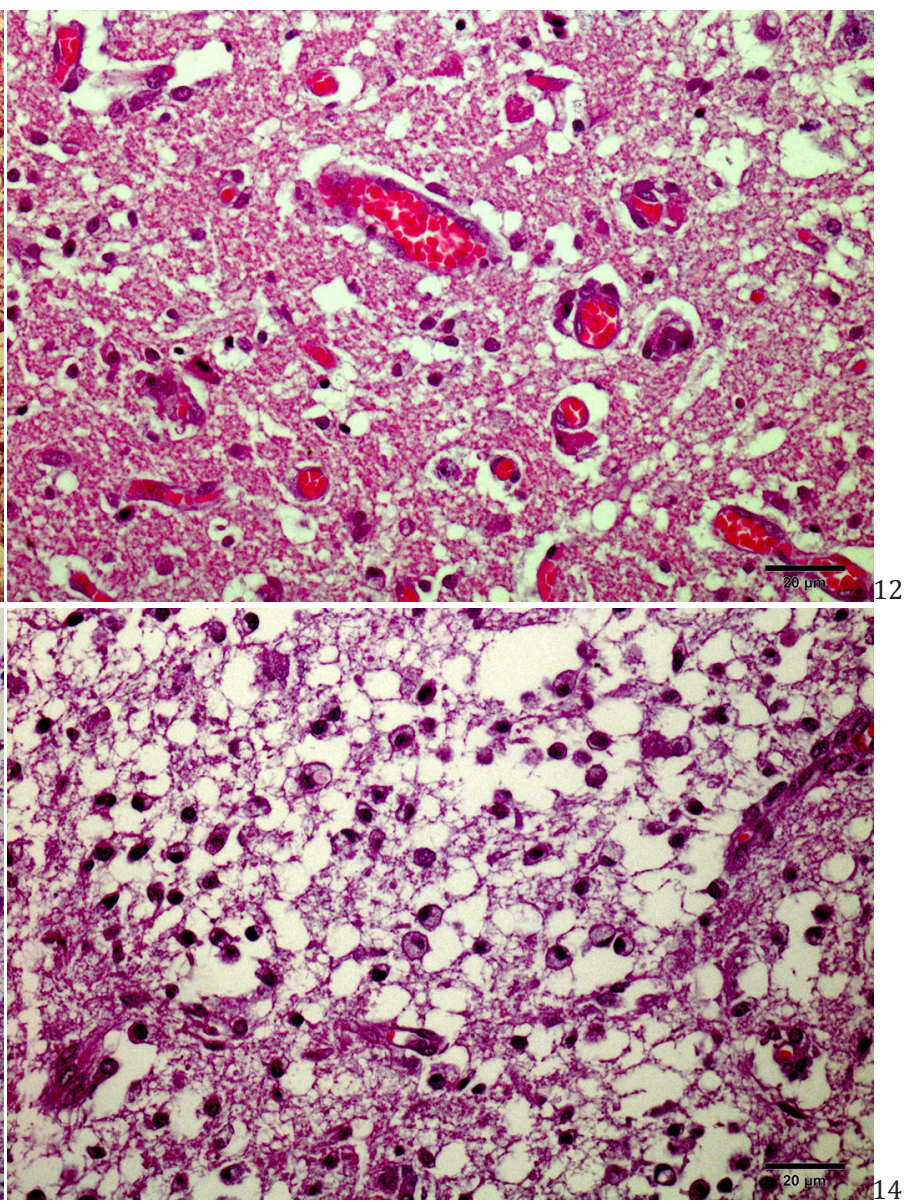

Fig.12. Intoxicação por sal em suínos. Observa-se que os capilares são proeminentes devido ao acentuado edema das células endoteliais. HE, obj.40x.

Fig.14. Intoxicação por sal em suínos. Seção de telencéfalo com malacia acentuada e grande quantidade de macrófagos espumosos (células Glitter) HE, obj.40x.

mum (alimento cozido com sal, alimentação com salmoura ou soro de leite). Esses alimentos são bem descritos como causa de intoxicação por sal em suínos (Bohstedt \& Grummer 1954, Smith 1955, Radostits et al. 2007, Thompson 2007). No Surto 5 , acredita-se que a grande quantidade de cloreto de sódio estava presente no soro de leite, a única fonte de líquido disponível aos porcos. Condições similares são relatadas quando somente o soro é a única fonte de água para os animais (Brito et al. 2001). Embora não tenha sido precisamente determinado, o tratador da Propriedade 2 relatou que o suprimento do soro foi interrompido por um período de tempo não determinado e que água pura foi fornecida nas mesmas tubulações que alimentavam os bebedouros dos leitões. Conforme já dito, restrições no fornecimento de água para suínos podem resultar em doença clínica (Radostits et al. 2007) quando os animais têm acesso ilimitado à água (Carson 2006, Radostits et al. 2007) o que pode ter acontecido nestes casos, se o tempo em que os animais ficaram sem receber o soro até o reestabelecimento da água foi longo.

Inicialmente os animais apresentam sede e constipação. Porém esses sinais quase nunca são observados (Radostits 
Quadro 1. Resultados referentes às dosagens de sódio em músculo, fígado, soro, líquor e humor aquoso de 15 suínos intoxicados espontaneamente por sal

\begin{tabular}{cccccc}
\hline Suíno & $\begin{array}{c}\text { Músculo } \\
(\mu \mathrm{g} / \mathrm{g})\end{array}$ & $\begin{array}{c}\text { Fígado } \\
(\mu \mathrm{g} / \mathrm{g})\end{array}$ & $\begin{array}{c}\text { Soro } \\
(\mathrm{mEq} / \mathrm{l})\end{array}$ & $\begin{array}{c}\text { Líquor } \\
(\mathrm{mEq} / \mathrm{l})\end{array}$ & $\begin{array}{c}\text { Humor aquoso } \\
(\mathrm{mEq} / \mathrm{l})\end{array}$ \\
\hline 1 & 2.011 & 2.930 & 227 & $\mathrm{ND}$ & 254 \\
2 & 1.780 & 3.039 & 160 & 171 & 181 \\
3 & 1.479 & 3.016 & 214 & 212 & 201 \\
4 & 1.024 & 3.623 & 203 & $\mathrm{ND}$ & 225 \\
5 & 2.633 & 3.228 & 211 & $\mathrm{ND}$ & 220 \\
6 & 1.537 & 2.928 & 199 & $\mathrm{ND}$ & 248 \\
7 & 2.385 & 3.823 & 211 & 224 & 212 \\
8 & 1.954 & 3.254 & 213 & 236 & 90 \\
9 & 2.092 & 3.607 & 200 & $\mathrm{ND}$ & 207 \\
10 & 1.624 & 3.006 & 221 & 278 & 321 \\
11 & 2.071 & 3.290 & 183 & $\mathrm{ND}$ & 260 \\
12 & 1.857 & 2.883 & 155 & 160 & 158 \\
13 & 1.756 & 3.054 & 220 & 252 & 258 \\
14 & 1.556 & 2.656 & 171 & $\mathrm{ND}$ & 164 \\
15 & 11.667 & 2.949 & 223 & $\mathrm{ND}$ & 187 \\
& & & & &
\end{tabular}

et al. 2007), conforme aqui relatado. Quando a dose de sal é muito elevada pode haver diarreia e vômito (Radostits et al. 2007), como observado no Surto 2. De acordo com o descrito em três surtos (3-5) revisados, há repentino desenvolvimento de sinais característicos do sistema nervoso central: convulsões intermitentes a cada três minutos são observadas após 24 horas de privação de água. Assim que os animais retomam o acesso à água, os sinais tornam-se acentuados. Entre os episódios convulsivos os animais podem desenvolver andar em círculos ou andar a esmo, cegueira aparente, tremores musculares, severa depressão, opistótono, posição de cão sentado e podem manter a cabeça pressionada contra a parede (Summers et al. 1995, Brito et al. 2001, Thompson 2007, Finnie et al. 2010, Boss et al. 2012, Sobestiansky et al. 2012). No Surto 5, com o maior acompanhamento dos animais, pode-se observar toda a evolução desses sinais. Os sinais clínicos duram poucas horas até seis dias e culminam com decúbito lateral, movimentos de pedalagem e morte (Radostits et al. 2007). Raros animais sobrevivem, como pode ser observado no Surto 5.

Macroscopicamente as lesões são inespecíficas. Pode-se observar congestão da mucosa do trato gastrointestinal. No sistema nervoso central pode haver hiperemia das leptomeninges (Summers et al. 1995, Thompson 2007, Boss et al. 2012, Sobestiansky et al. 2012). Este achado foi observado em dois surtos (3 e 5). Microscopicamente há duas lesões características. A primeira é a infiltração de eosinófilos nas leptomeninges e no espaço de Virchow-Robin do córtex cerebral (Smith 1957), observada em todos os surtos revisados. A segunda é a necrose cortical laminar (Done et al. 1957, Done et al. 1959), vista com maiores detalhes no Surto 5. Cada uma dessas lesões ocorre separadamente, mas quando observadas juntas no mesmo animal, como no caso destes leitões, são consideradas patognomônicas (Maxie \& Youssef 2007). É descrito que a meningoencefalite eosinofílica é mais marcada nas primeiras 24 horas e que os eosinófilos são gradualmente substituídos por células mononucleares (Moreno et al. 2007). Nos casos de lesões avançadas, áreas de malacia cortical podem ser ob- servadas (Maxie \& Youssef 2007). No Surto 5, como foram necropsiados suínos em diferentes fases da doença, pode-se observar claramente a evolução da meningoencefalite eosinofílica (animais necropsiados um dia após o início dos sinais), para uma marcada necrose neuronal laminar, com malacia (animais necropsiados seis dias após o início dos sinais clínicos).

A localização das lesões encefálicas predominantemente nas seções de telencéfalo examinadas está de acordo com a maioria dos autores (Smith 1955, Smith 1957, Done et al. 1959, Rac et al. 1959, Summers et al. 1995, Radostitis 2007, Boos et al. 2012) . Há um relato na literatura (Satoh 1961) em que lesões de mesma intensidade também podem ser observadas no mesencéfalo e no bulbo, porém isso não foi condizente com nossos casos onde nessas seções as lesões eram leves ou ausentes. A hiperemia e proeminência de vasos sanguíneos observadas predominantemente nos locais de lesão mais acentuada são descritas por autores mais antigos como "proliferação de vasos sanguíneos" (Smith 1955, Done et al. 1959, Satoh 1961). Recentemente a presença de astrócitos Alzheimer tipo II, em adição as lesões patognomônicas combinadas (necrose cerebrocortical laminar e infiltrado de eosinófilos), foram descritas no cérebro de suínos afetados por intoxicação indireta por sal seguida de privação de água (Finnie et al. 2010, Boos et al. 2012). Os autores descrevem estas células na microscopia de luz, com preparações histológicas coradas com hematoxilina e eosina, como um núcleo grande e vacuolizado e citoplasma escasso. Aqui neste estudo essas células não foram identificadas. Gliose e neuronofagia não são foram lesões comumente observadas, o que está de acordo com a literatura (Done et al. 1959).

Em quatro suínos a contagem de eosinófilos circulantes estava dentro dos limites normais descritos na literatura por Smith (2009) (50-2.000 eosinófilos por $\mu \mathrm{L}$ de sangue). Porém, nos outros sete suínos, a quantidade de eosinófilos circulantes foi nula. Isso indica que esses animais apresentavam eosinopenia. A literatura (Radostits et al. 2007) descreve que somente animais da espécie suína intoxicados por sal podem desenvolver esta alteração, principalmente quando estão próximos da morte. Nesta espécie acredita-se que isso ocorra por causa do grande recrutamento dessas células para o local da lesão. 0 motivo da encefalite inicial ser predominantemente eosinofílica no suíno ainda é desconhecido (Summers et al. 1995). Há um autor que acredita que o íon sódio atraia eosinófilos (Done et al. 1959), mas em outro estudo, em que foi injetado sal diretamente no encéfalo, não foi observada esta alteração (Smith 1955). Este último autor relata ainda que eosinopenia acompanha todo o curso dos sinais clínicos da doença, exatamente como observado, e que os animais que se recuperam logo têm seus níveis reestabelecidos.

As concentrações de sódio nos fragmentos de fígado foram extremamente altas em todos os suínos que foram submetidos à eutanásia no Surto 5. A literatura cita que valores acima de $150 \mu \mathrm{g} / \mathrm{g}$ no cérebro e no fígado são considerados indicativos de intoxicação por sal em suínos devido ao acúmulo deste íon em todos os tecidos corporais (Radostits et al. 2007). A concentração de sódio no fígado dos suínos do 
Surto 5 foi entre 17 e 25 vezes maior que este valor. Estes valores tão exuberantes são semelhantes aos descritos para as concentrações de sódio no encéfalo de bovinos com a mesma alteração (Radostits et al. 2007). Em relação à concentração de sódio no músculo, acredita-se que também esteja extremamente elevada, porém dados na literatura que comprovem estes dados não foram encontrados.

Com relação aos resultados das concentrações de sódio no soro observados em 15 suínos do Surto 5, todas estão acima dos limites normais descritos na literatura de 135-145mEq/L (Dow et al. 1963, Pearson \& Kallfelz 1982, Wells et al. 1984, Scarratt 1985, Radostits et al. 2007, Thompson 2007). Em um estudo (Smith 1955) esse dado é usado como forma de diagnóstico da doença. Com relação aos valores da dosagem de sódio no humor aquoso, apenas um dos suínos está abaixo dos valores comumente observado nesta doença (172-218 mEq/L). Para bovinos o nível normal de sódio no líquor é de $140 \mathrm{mEq} / \mathrm{L}$, valor relativamente inferior a todos os observados aqui (Pringle \& Berthiaume 1988). 0 mesmo autor descreve ainda que com o passar das horas, os níveis tender a subir pelo menos até seis horas pós-intoxicação.

Todas as alterações observadas podem ser explicadas pela provável patogenia da doença descrita na literatura e comprovam a intoxicação por cloreto de sódio (Radostitis 2007, Thompson 2007, Finnie 2010). Edema cerebral foi uma das lesões mais características e observadas em quase todas as seções de encéfalo do Surto 5. Acredita-se que seja ocasionada devido à tentativa de se reestabelecer o balanço osmótico, desestabilizado pela exorbitante quantidade de sal acumulada no organismo. A grande quantidade de sal acumulada pode ser comprovada pelas dosagens do íon sódio no fígado, músculo, líquor, soro e humor aquoso. 0 edema levou ao aumento da pressão intracraniana e decréscimo da perfusão para o cérebro causando isquemia difusa e necrose neuronal, com consequente malacia. Somente a infiltração de eosinófilos observada em todos os surtos não pode ter sua origem concretamente estabelecida, somente foi comprovada pela eosinopenia descrita no Surto 5. Acreditamos que seja particularidade da espécie.

Nos diagnósticos diferenciais para as doenças neurológicas de suínos jovens podemos incluir as encefalomielites virais, como a doença de Aujeszky (DA), doença do edema e meningites por estreptococos (ME) (Carson 2006). A severidade dos sinais clínicos observados no Surto 5 aqui descrito é geralmente visto em suínos jovens (com até 30 dias) com DA. Porcos mais velhos raramente apresentam sinais neurológicos e, mesmo assim, de pouca intensidade. Hepatite necrosante multifocal é outro achado que diferencia a DA (Zachary 2007). A infiltração eosinofílica não ocorre associada com encefalite necrosante observada na DA e corpúsculos de inclusão intranucleares nos neurônios também podem ser observados, embora não constantes. Febre é um sinal clínico distinto observado na ME e, nessa doença, a mortalidade nunca é tão elevada como a observada nos surtos de intoxicação por sal. As lesões observadas histologicamente são de leptomeningite fibrinossupurativa. Na doença do edema, os porcos afetados têm entre quatro e oito semanas de idade, sendo que animais mais jovens ou mais velhos podem ser acometidos (Zachary 2007). A morbidade é baixa e edema é observado em vários órgãos. A lesão primária observada na histologia, angiopatia e vasculite degenerativas, é mais frequente e mais acentuada na região do diencéfalo e nas meninges (Zachary 2007). As lesões angiopáticas precedem a malacia.

\section{REFERÊNCIAS}

Arieff A.I. \& Guisado R. 1976. Effects on the nervous system of hypernatremic and hyponatremic states. Kidney International 10:104-116.

Bohstedt G. \& Grummer R.H. 1954. Salt poisoning of pigs. J. Anim. Sci. 13:933-939.

Boos G.S., Watanabe T.T.N., Almeida P.R., Oliveira L.G.S., Pavarini S.P., Zlotowski P. \& Driemeier D. 2012. Surto de intoxicação por sal em suínos em Santa Catarina. Pesq. Vet. Bras. 32:329-332.

Brito L.A., Matos M.P., Sobestiansky J., Sucupira M.C. \& Ortolani E.L. 2001. Accumulative sodium poisoning in Brazilian swine fed whey. Vet. Hum. Toxicol. 43:88-90.

Carson T.L. 2006. Toxic minerals, chemicals, plants, and gases, p.971-984. In: Straw B.E., Zimmerman J.J., D’Allaire S. \& Taylor D.J. (Eds), Diseases of Swine. $9^{\text {th }}$ ed. Blackwell Publishing, Ames.

Corby H. 1856. Trismus in two pigs supposed to be caused by the giving of some brine. The Veterinarian 29:462.

Cox D.H. \& Pitts J.C. 1957. The clinical picture of salt poisoning of swine. J. Am. Vet. Med. Assoc. 130:176-177.

Done J.T., Harding J.D.J. \& Lloyd M.K. 1957. Meningoencephalitis eosinophilic of swine: 1 , the naturally occurring disease. Vet. Rec. 69:67-70.

Done J.T., Harding J.D.J. \& Lloyd M.K. 1959. Meningo-encephalitis eosinophilica of swine. 2. Studies on the experimental reproduction of the lesions by feeding sodium chloride and urea. Vet. Rec. 71:92-96.

Dow C., Lawson G.H.K. \& Todd J.R. 1963. Sodium sulphate toxicity in pigs. Vet. Rec. 75:1052-1055.

Finnie J.W., Blumbergs P.C. \& Williamson M.M. 2010. Alzheimer type II astrocytes in the brains of pigs with salt poisoning (water deprivation/ intoxication). Aust. Vet. J. 88:405-407.

Gellatly J.B.M. 1957. Discussion of paper by Done, J.T. (1957). Vet. Rec. 69:1351.

Gamgee J. 1856. On poisoning of pigs with brine. The Veterinarian 29:647.

Grummer R.H. \& Bohstedt G. 1947. Can 'salt poisoning' kill pigs? Wis. Agr. Exp. Sta. Bull. 50-51.

Innes J.R.M. \& Saunders L.Z. 1962. Comparative Neuropathology. Academic Press, New York, p.707-708.

Jackman R. \& Edwin E.E. 1983. Cerebral autofluorescence and thiaminase deficiency in cerebrocortical necrosis. Vet. Rec. 112:548-550.

Lepper H. 1856. On poisoning of pigs brine. The Veterinarian 29:434-436. Lewis G. 1856. Poisoning of pigs with brine. The Veterinarian 29:518-522.

Maxie M.G. \& Youssef S. 2007. Nervous system, p.281-457. In: Maxie M.G. (Ed.), Jubb, Kennedy, and Palmer's Pathology of Domestic Animals. Vol.1. $5^{\text {th }}$ ed. Saunders Elsevier, Philadelphia.

Moreno A.M., Sobestiansky J. \& Morés N. 2007. Intoxicações por minerais, produtos químicos, plantas e gases, p.461-486. In: Sobestiansky J., Barcellos D. (Eds), Doenças dos Suínos. Cânone Editorial, Goiânia.

Morton W.J.T. \& Simonds J.B. 1856. On the poisonous properties of brine. The Veterinarian 29:356-358.

Nicholson J. 1945. Lander's Veterinary Toxicology. $3^{\text {rd }}$ ed. Alexander Eger Inc, Chicago. (Apud Smith 1955)

Padovan D. 1980. Polioencephalomalacia associated with water deprivation in cattle. Cornell Vet. 70:153-159.

Pearson E.G \& Kallfelz F.A. 1982. A case of presumptive salt poisoning (water deprivation) in veal calves. Cornell Vet. 72:142-149.

Pringle J.K. \& Berthiaume L.M.M. 1988. Hypernatremia in calves. J. Vet. Intern. Med. 2:66-70. 
Rac R., Bray J.H. \& Lynch J. 1959. Meningo-encephalitis eosinophilica of pigs. Vet. Rec. 71:688-691.

Radostits O.M., Gay C.C., Hinchcliff K.W. \& Constable P.D. 2007. Diseases associated with inorganic and farm chemicals, p.1824-1826. In: Ibid. (Eds), Veterinary Medicine: a textbook of the diseases of cattle, horses, sheep, pigs and goats. $10^{\text {th }}$ ed. Saunders Elsevier, Edinburgh.

Satoh H. 1961. Neuro-histopathological studies on so-called "encephalitis eosinophilica suis". Japn. J. Vet. Res. 9:41-115.

Sautter J.H., Sorenson D.K. \& Clark J.J. 1957. Symposium on poisoning. 1. Salt poisoning in swine. J. Am. Vet. Med. Assoc. 130:12-13.

Scarratt K., Collins T.J. \& Sponenberg D.P. 1985. Water deprivation-sodium chloride intoxication in a group of feeder lambs. J. Am. Vet. Med. Assoc. 186:977-978.

Slavin G. \& Worden A.N. 1941. Salt poisoning in pigs. Vet. Rec. 53:694-699.

Smith B.P. 2009. Large Animal Internal Medicine. $4^{\text {th }}$ ed., Mosby Elsevier, St Louis.

Smith D.L.T. 1955. Sodium salt poisoning in swine. PhD thesis in Veterinary Pathology, Cornell University, Publication no15-621, Ithaca, NY. 165p.

Smith D.L.T. 1957. Poisoning by sodium salt: a cause of eosinophilic meningoencephalitis in swine. Am. J. Vet. Res. 18:825-850.
Smith D.L.T. 1958. Sodium salt poisoning, p.469-476. In: Dunne H.W. (Ed.), Diseases of Swine. Iowa State College Press, Ames.

Sobestiansky J., Morés N., Souza M.A. \& Moreno A.M. 2012. Intoxicações por minerais, produtos químicos, plantas e gases, p.551-580. In: Sobestiansky J. \& Barcellos D. (Eds), Doenças dos Suínos. 2ª ed. Cânone Editorial, Goiânia.

Summers B.A., Cummings J. \& De Lahunta A. 1995. Degenerative diseases of the central nervous system: salt poisoning, p.254-255. In: Ibid. (Eds), Veterinary Neuropathology. Mosby, St Louis.

Thompson L.J. 2007. Sodium chloride (salt), p.461-464. In: Gupta R.C. (Ed.), Veterinary Toxicology: basic and clinical principles. Academic Press, New York.

Vianna A.T. 1976. Os suínos: criação prática e econômica. 6ª ed. Nobel, São Paulo.

Wells G.A.H., Lewis G., Hawkins S.A.C. \& Don P.L. 1984. Evaluation of brain chloride determinations in the diagnosis of water deprivation/sodium salt intoxication in pigs. Vet. Rec. 114:631-635.

Zachary F. 2007. Nervous system, p.833-971. In: McGavin M.D. \& Zachary J.F. (Eds), Pathologic Basis of Veterinary Disease. $5^{\text {th }}$ ed. Mosby Elsevier, St Louis. 